\title{
ON A METHOD OF CALCULATING FLUIDITY, SURFACE TENSION AND REACTION (EQUILIBRIUM) PRESSURE.*
}

\author{
BY \\ HENRY JERMAIN MAUDE CREIGHTON, D.Sc. \\ - Department of Chemistry, Swarthmore College; Member of the Institute.
}

Some years ago it was shown by Ramsay and Young ${ }^{1}$ that for any pair of closely related substances-such as methyl acetate and ethyl acetate, or propyl propionate and propyl butyrate-the ratio of the absolute temperatures $(T)$ corresponding to equal vapour pressures is constant, i.e., $T_{A}^{\prime} / T_{B}^{\prime}=T_{A} / T_{B}=$ a constant. For substances not closely related, it was found that the relation was less simple, but that it might be expressed by the equation $R^{\prime}=R+c\left(T_{B}^{\prime}-T_{B}\right)$, where $R^{\prime}$ is the ratio of the absolute temperatures of the two substances corresponding to any vapour pressure, the same for both; $R$ is the ratio of the absolute temperatures at any other vapour pressure, again the same for both; and $T_{B}^{\prime}$ and $T_{B}$ are the temperatures of one of the substances corresponding to the two vapour pressures. This relationship, which was tested by Ramsay and Young for 23 pairs of substances, has been found to hold up to the critical point. The method has been employed by Ramsay and Travers ${ }^{2}$ to calculate the vapour pressures of the inert gases, argon, krypton and xenon, at various temperatures.

At the suggestion of Ramsay, Findlay ${ }^{3}$ showed that a precisely similar equation to that of Ramsay and Young connects the absolute temperatures at which two substances have equal solubilities, and also the absolute temperatures at which two chemical equilibria have equal equilibrium constants.

The writer has found that the absolute temperatures at which two substances have the same value for certain other physical constants are related by an expression having the same form as the Ramsay and Young vapour pressure equation. In this paper the relations between the absolute temperature and fluidity, the

* Communicated by Professor Creighton.

${ }^{1}$ Phil. Mag. (5), 20, 515 (I885); 21, 33 (1886).

${ }^{2}$ Phil. Trans., A., 197, 47 (1901).

${ }^{3}$ Proc. Roy. Soc., 69, 471 (1902). 
absolute temperature and surface tension, and the absolute temperature and reaction pressure (equilibrium pressure) are presented briefly.

The constant, $c$, in the equation $R^{\prime}=R+c\left(T_{B}^{\prime}-T_{B}\right)$, where $R^{\prime}$ and $R$ are the ratios of the absolute temperatures of two substances, $A$ and $B$, corresponding to two values of the physical constant, is determined as follows: Values of the ratio $R^{\prime}=T_{A}^{\prime} / T_{B}$, corresponding to a number of different values of

TABLE I.

Calculation of the Fluidity of Octane (A) from the Fluidity of Benzene (B).

$c=0.000354$.

\begin{tabular}{|c|c|c|c|c|c|c|}
\hline \multirow{2}{*}{$\underset{\phi}{\text { Fluidity }}$} & \multicolumn{2}{|c|}{$\begin{array}{c}\text { Observed Absolute } \\
\text { Temperaturet. }\end{array}$} & \multirow{2}{*}{$\begin{array}{c}\text { Ratio of } \\
\text { Observed } \\
\text { Temperatures } \\
T_{A}^{\prime}{ }_{A} / T_{B}^{\prime}{ }_{B}\end{array}$} & \multirow{2}{*}{$\begin{array}{c}\text { Calculated } \\
\text { Absolute } \\
\text { Temperature } \\
T_{A}^{\prime}\end{array}$} & \multirow{2}{*}{$\begin{array}{l}\text { Calculated } \\
\text { Fluidity of } \\
\text { Octane } \\
\phi \text { calcd. }\end{array}$} & \multirow{2}{*}{$\begin{array}{l}\text { Difference } \\
\phi \text { calcd. }-\phi \phi\end{array}$} \\
\hline & $\underset{T_{A}^{\prime}}{\text { Octane }}$ & $\left|\begin{array}{c}\text { Benzenes } \\
T_{B}^{\prime}\end{array}\right|$ & & & & \\
\hline $\mathrm{I} 42.2$ & 273.1 & 287.6 & 0.9497 & 273.4 & 142.6 & +0.4 \\
\hline 163.2 & 283.1 & 296.8 & $0.9540^{*}$ & $283 . I$ & I 63.2 & 0.0 \\
\hline I 74.8 & 288.1 & 301.5 & 0.9557 & $288 . \mathrm{I}$ & I 74.8 & 0.0 \\
\hline 185.9 & 293.1 & $306 . \mathrm{I}$ & 0.9576 & 293.0 & 185.7 & -0.2 \\
\hline 197.4 & 298.1 & 310.8 & $0.959 \mathrm{I}$ & 298.0 & 197.2 & -0.2 \\
\hline 209.9 & 303.1 & 315.5 & 0.9605 & 303.2 & 209.2 & +0.2 \\
\hline 233.7 & 313.1 & 324.9 & 0.9637 & 313.1 & 233.7 & 0.0 \\
\hline 259.4 & 323.1 & $334 . I$ & 0.9673 & 322.8 & 258.8 & -0.6 \\
\hline 286. I & $333 \cdot I$ & 343.4 & $0.970 \mathrm{I}$ & 333.2 & 286.3 & +0.2 \\
\hline
\end{tabular}

† In most of the examples which follow, the $T_{A}^{\prime}$ values are direct observations, while the $T_{B}^{\prime}$ values have been obtained by interpolation of experimental data.

the physical constant, are plotted against the absolute temperatures, $T_{B}^{\prime}$, of one of the substances. A straight line is then drawn through the series of points obtained and "smoothed ratios" read off, corresponding to the temperatures $T_{B}^{\prime}$. The values of the smoothed ratios are substituted in the equation $R^{\prime}=R+c\left(T_{B}^{\prime}-T_{B}\right)$ and the equation solved for $c$.

The success with which the fluidity $(\phi)$ of liquids can be calculated by means of the equation, $R^{\prime}=R+c\left(T_{B}^{\prime}-T_{B}\right)$, is illustrated by the examples given in Tables I and II. The former table gives in detail data obtained with octane $(A)$ and benzene $(B)$, while the latter, summarizing the results obtained, using propyl iodide $(A)$ and perchlorethylene $(B)$ and water $(B)$ with each of several liquids $(A)$, gives the "observed" and "calcu-

"Landolt-Börnstein, "Physikalisch-Chemische Tabellen,” p. 78, Berlin, I9I2.

${ }^{5}$ Ibid., p. 80 . 
lated" absolute temperatures at which liquid $A$ has a definite fluidity. In these and the following tables the asterisk denotes the temperature ratio $R$ (or the absolute temperatures $T_{A}$ and $T_{B}{ }_{B}$, where $T_{A} / T_{B}=R$ ), from which the other temperature ratios $\left(R^{\prime}\right)$ and the corresponding absolute temperatures $\left(T_{A}^{\prime}\right)$ have been calculated.

It will be observed that the calculated and observed values in these tables agree very well, except in the case of mercury and water. This lack of agreement is partly due, at least, to the flatness of the fluidity-temperature curve of mercury, in consequence of which a small error in the fluidity gives a comparatively large error in the calculated value of the absolute temperature. Above $T_{A}^{\circ}=427 . \mathrm{I}^{\circ}$, the difference between the observed and calculated absolute temperatures increases rapidly with rise in temperature. This may well be due to inaccuracies in the experimental data, since the values for the viscosity of mercury at high temperatures, as determined by Koch ${ }^{6}$ and by Plïss, ${ }^{7}$ differ considerably. It should be noted that much better agreement over a greater range has been obtained with fluidity values based on Koch's viscosity mesaurements than with those based on Plïss' determinations.

A number of other pairs of liquids that have been studied are given in Table III. With one exception, the agreement between the observed and calculated values of $T_{A}^{\prime}$, over the temperature interval studied, is as close as that given in Tables I and II. Indeed, in most cases, the agreement between the observed and calculated fluidity is closer than the values determined by different investigators. The pair of liquids, ethyl alcohol: water, does not follow the equation $R^{\prime}=R+c\left(T_{B}^{\prime}-T_{B}\right)$ even approximately. With these two liquids the temperature ratio $T_{A}^{\prime} / T_{B}^{\prime}$, when plotted against $T_{B}^{\prime}$, instead of changing linearly, at first increases rapidly as $T_{B}^{\prime}$ increases, then more slowly and finally decreases. With aniline and water the agreement is good over the fluidity range given in the table, but the difference between the observed and calculated temperatures increases rapidly above the upper limit given for the fluidity. This is hardly surprising, as at higher temperatures values for the viscosity of aniline determined by different observers vary by 20 per cent. or more (e.g., the values

"Wied. Ann., I4, I (188I).

'Z. anorg. Chem., 93, I (1915). 
650

H. J. M. Cineighton.

[J. F. I.

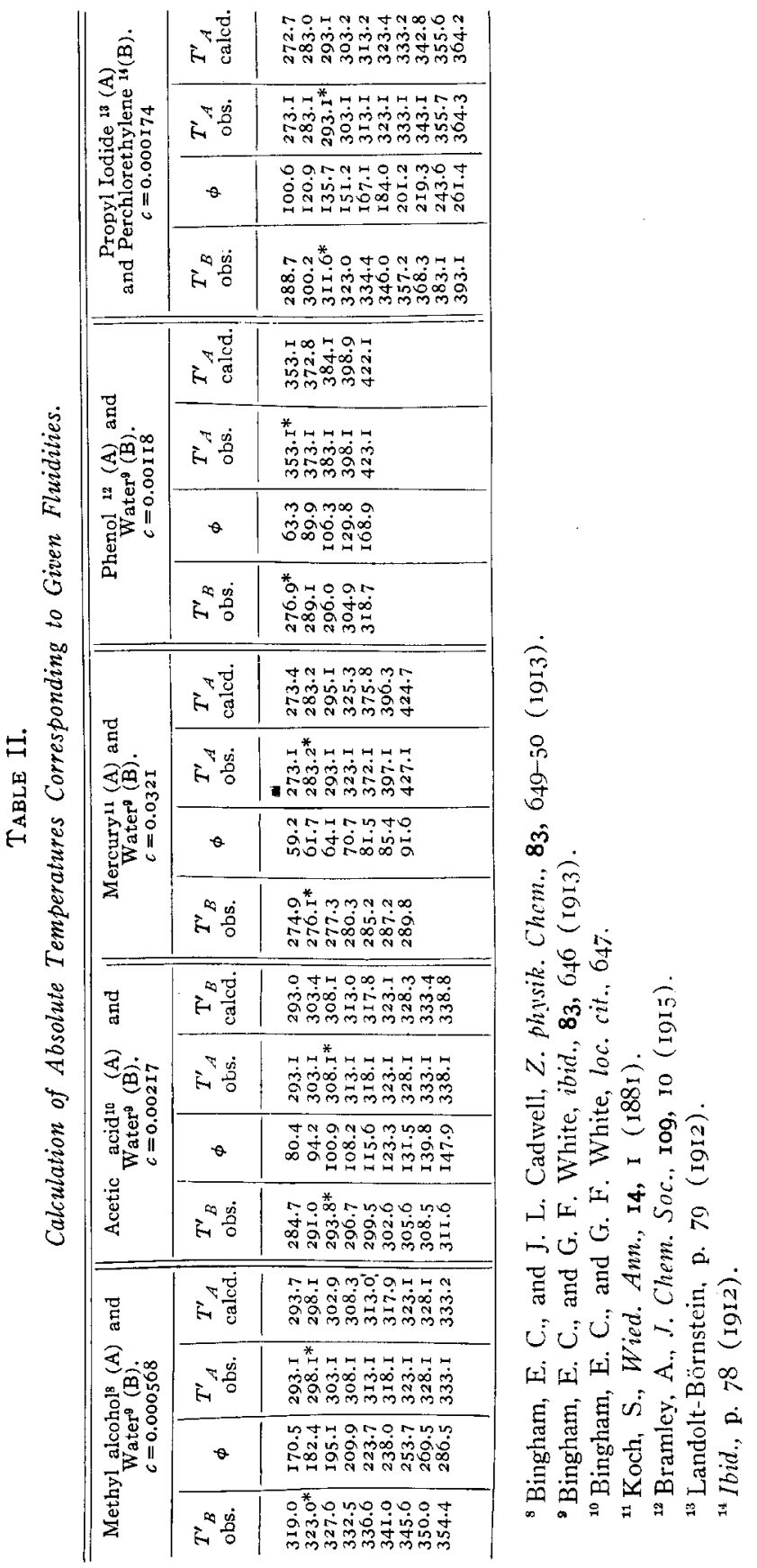


determined at $\mathrm{I} 25^{\circ} \mathrm{C}$. by Bramley ${ }^{18}$ and by Kurnakow, Krotkow and Oksman ${ }^{19}$ ).

It was thought that the surface tension $(\gamma)$ and absolute temperature of liquids might also be connected by an equation having the form, $R^{\prime}=R+c\left(T_{B}^{\prime}-T_{B}\right)$, where $R^{\prime}$ and $R$ are the ratios of the absolute temperatures at which two liquids, $A$ and $B$, have the same surface tensions. Unfortunately, it has only been possible to test the relation with a few pairs of liquids, owing to lack of experimental surface tension data covering a wide range. With the pairs of liquids studied, the agreement between the

TABLE III.

\begin{tabular}{|c|c|c|c|}
\hline \multicolumn{2}{|c|}{ Liquids. } & \multirow{2}{*}{ Fluidity Intervals. } & \multirow{2}{*}{$c$} \\
\hline$A$ & $B$ & & \\
\hline $\begin{array}{l}\text { Pyridine }{ }^{15} \ldots \ldots \ldots \\
\text { Acetic acid } 16 \ldots \ldots \\
\text { Propionic acid }{ }^{17} \ldots \\
\text { Aniline }{ }^{15} \ldots \ldots \ldots \\
\text { Quinoline }{ }^{15} \ldots \ldots \ldots \\
\text { Dimethylaniline }{ }^{15} \ldots \\
\text { Phenetole }{ }^{15} \ldots \ldots \ldots \\
\text { Ethyl alcohol }{ }^{16} \ldots \ldots\end{array}$ & $\begin{array}{l}\text { Water }{ }^{9} \\
\text { Propionic acid }^{17} \\
\text { Water }^{9} \\
\text { Water }^{9} \\
\text { Water }^{9} \\
\text { Water }^{9} \\
\text { Water }^{9} \\
\text { Water }^{9}\end{array}$ & $\begin{array}{l}75.6-259.7 \\
80.4-164.6 \\
84.5^{-202.0} \\
64.7-157.0 \\
59.8-182.8 \\
49.4^{-1} 52.0 \\
53.8-179.2 \\
91.0-212.5\end{array}$ & $\begin{array}{c}0.00200 \\
-0.000194 \\
0.00218 \\
0.00174 \\
0.00370 \\
0.00267 \\
0.00184 \\
\text { not constant }\end{array}$ \\
\hline
\end{tabular}

observed and calculated temperatures is good, as is illustrated by the data recorded in Table IV. In addition to those given in this table, the following pairs of liquids ${ }^{21}$ have been studied: anisol and diethyl chloromaleate, diethyl phenylpropionate and thiophenol, diethylmaleate and toluene, and triphenylphosphine and triphenylstibine. It will be observed that not only does the relation hold for non-associated liquids (e.g., bromtoluene and chlorbenzene), but that it also holds for an associated and a nonassociated liquid (e.g., acetic acid and toluene). In view of the good agreement obtained with the few examples studied, it is probable that, when additional surface tension data become available, the expression, $R^{\prime}=R+c\left(T_{B}^{\prime}-T_{B}\right)$, will be found to hold for other pairs of liquids.

\footnotetext{
${ }^{15}$ Bramley, A., J. Chem. Soc., ıog, 10, 434 (1916).

"Bingham, E. C., and G. F. White, loc. cit.

${ }^{17}$ Dunstan, A. E., J. Chem. Soc., 107, 667 (1915).

${ }^{18}$ Loc. cit.

${ }^{19}$ Bl. Acad. Sc. Pét., 9, 45.
} 
It has also been found that the equilibrium pressure (reaction or decomposition pressure) of various chemical reactions in solid-gas, or wholly gaseous, systems can be calculated at different temperatures by means of the expression, $R^{\prime}=R+c\left(T^{\prime}{ }_{B}-T_{B}\right)$. Here $R^{\prime}$ is the ratio of the absolute temperatures at which two reactions, $A$ and $B$, have the same equilibrium pressure, and $R$ is the ratio of the absolute temperatures corresponding to another value of the equilibrium pressure, the same for both reactions. A number of types of reactions has been studied and, for pairs

TABLE IV.

Calculation of Absolute Temperatures Corresponding to Given Surface Tensions.

\begin{tabular}{|c|c|c|c|c|c|c|c|}
\hline \multicolumn{4}{|c|}{$\begin{array}{c}\text { Acetic Acid }{ }^{20}(A) \text { and Tolune }{ }^{21}(B) ; \\
\qquad C=0.000270\end{array}$} & \multicolumn{4}{|c|}{$\begin{array}{l}\text { Bromtoluene }{ }^{22}(A) \text { and Chlorbenzene } 21 \\
\qquad=\text { zero }\end{array}$} \\
\hline$T_{B}^{\prime}$ obs. & $\boldsymbol{\gamma}$ & $T^{\prime}{ }_{A}$ obs. & $T_{A}^{\prime}$ calcd & $T_{B}^{\prime}$ obs. & $\gamma$ & $T_{A}^{\prime}$ obs. & $T_{A}^{\prime}$ calcd. \\
\hline 299.0 & 26.87 & 303.1 & 302.6 & 287.7 & 32.992 & $283 . \mathrm{I}$ & 282.9 \\
\hline $308.6^{*}$ & 25.84 & $313 . I^{*}$ & 3 I3.I & $298 . I^{*}$ & 31.727 & 293. I $^{*}$ & 293. I \\
\hline 317.9 & 24.82 & $323 . I$ & 323.3 & 308.3 & $30.44 I$ & 303.I & 303.1 \\
\hline 327.0 & 23.80 & 333 . I & 333.4 & 318.3 & $29.5^{21}$ & 3I3. I & 313.0 \\
\hline 335.7 & 22.80 & 343.1 & 343. I & 328.5 & 28.079 & 323.1 & 323.0 \\
\hline 344.8 & 21.79 & 353.1 & 353.2 & 338.3 & 26.925 & 333.1 & 332.6 \\
\hline 353.9 & $20.8 \mathrm{I}$ & 363.1 & 363.5 & & & & \\
\hline 371.5 & I 8.90 & 383.1 & 383.2 & & & & \\
\hline
\end{tabular}

of reactions of the same general type, the agreement between the observed and calculated results has been good in most cases. With pairs of reactions of different types, e.g.,

$$
\begin{aligned}
& \text { (A) } \mathrm{AgP}_{2} \rightleftarrows \mathrm{AgP}+\mathrm{P} \text {, and } \\
& \text { (B) } 2 \mathrm{CuSO}_{4} \rightleftarrows 2 \mathrm{CuO}+2 \mathrm{SO}_{3} \text {, }
\end{aligned}
$$

the expression does not hold for two out of the three pairs studied. This may, however, be due to inaccurate experimental data rather than to anomalous behavior of the reacting substances. The results obtained with three pairs of reactions are given in Table $\mathrm{V}$, where it will be observed that the calculated absolute temperatures at which reaction $A$ has definite equilibrium pressures agree closely with the temperatures determined by experiment. Other pairs of reactions that have been studied are recorded in Table VI.

\footnotetext{
* Bennett, J. M., J. Chem. Soc., I07, 35I (1915).

${ }^{21}$ Walden, P., and R. Swinne, Z. physik. Chem., 79, 708 (I9r2).

${ }^{22}$ Müller, A. H. R., ibid., 86, 177 (I9I4).
} 


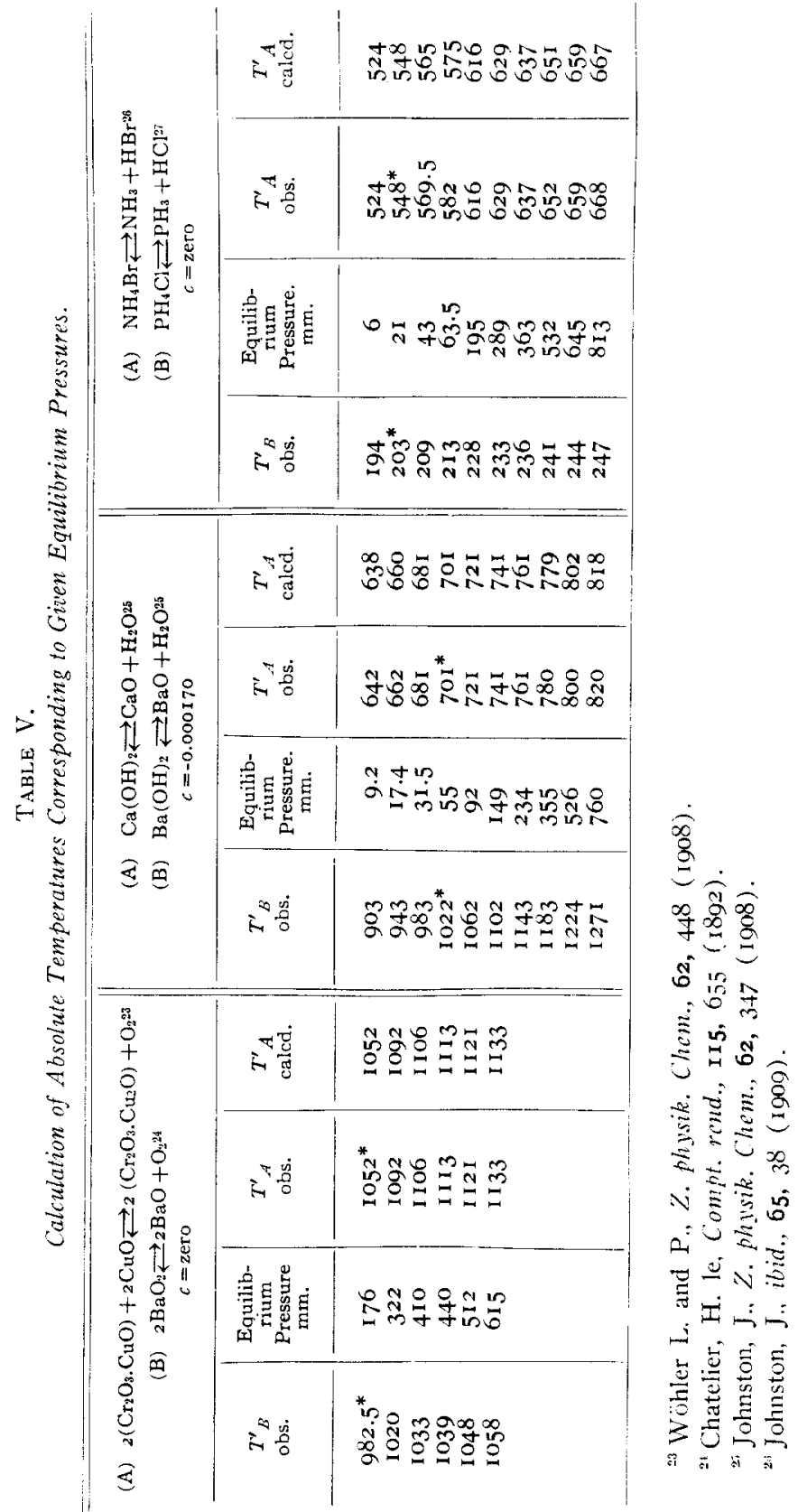


The data given in this paper show that, by means of an expression precisely similar to the Ramsay and Young vapour pressure equation, it is possible to calculate the fluidity (or viscosity) of liquids, the equilibrium pressure of chemical reactions and prob-

TABLE VI.

\begin{tabular}{|c|c|c|}
\hline Reactions & $\begin{array}{l}\text { Pressure } \\
\text { Intervals } \\
\text { mm. }\end{array}$ & $\begin{array}{c}\text { Constant } \\
c .\end{array}$ \\
\hline I. $\left\{\begin{array}{l}\text { (A) } 2 \mathrm{BaO}_{2} \rightleftarrows 2 \mathrm{BaO}+\mathrm{O}_{2}{ }^{24} \ldots \ldots \ldots \ldots \ldots \ldots \ldots \\
\text { (B) } 2 \mathrm{PbO}_{3} \mathrm{Ca} \rightleftarrows 2 \mathrm{PbO}_{2} \mathrm{Ca}+\mathrm{O}_{2}{ }^{24} \ldots \ldots \ldots \ldots \ldots \ldots\end{array}\right.$ & $65-670$ & zero \\
\hline 2. $\begin{cases}(\mathrm{A}) & 2\left(\mathrm{Cr}_{2} \mathrm{O}_{3} \cdot \mathrm{CuO}\right)+2 \mathrm{CuO} \underset{2}{\rightleftarrows}\left(\mathrm{Cr}_{2} \mathrm{O}_{3} \cdot \mathrm{Cu}_{2} \mathrm{O}\right)+\mathrm{O}_{2}{ }^{23} . \\
\text { (B) } & 2 \mathrm{PbO}_{3} \mathrm{Ca} \rightleftarrows 2 \mathrm{PbO}_{2} \mathrm{Ca}+\mathrm{O}_{2}{ }^{24} \ldots \ldots \ldots \ldots \ldots \ldots \ldots\end{cases}$ & I 76-795 & zero \\
\hline 3. $\left\{\begin{array}{l}\text { (A) }{ }_{2} \mathrm{CuBr}_{2} \rightleftarrows 2 \mathrm{CuBr}+\mathrm{Br}_{2}{ }^{28} \ldots \ldots \ldots \ldots \ldots \ldots \ldots \ldots \\
\text { (B) }{ }_{2} \mathrm{BaO}_{2} \rightleftarrows 2 \mathrm{BaO}+\mathrm{O}_{2}{ }_{2}^{24} \ldots \ldots \ldots \ldots \ldots \ldots \ldots\end{array}\right.$ & $22-597$ & not constant \\
\hline 4. $\left\{\begin{array}{l}\text { (A) } \mathrm{Sr}(\mathrm{OH})_{2} \rightleftarrows \mathrm{SrO}+\mathrm{H}_{2} \mathrm{O}^{25} \\
\text { (B) } \mathrm{Ba}(\mathrm{OH})_{2} \rightleftarrows \mathrm{BaO}+\mathrm{H}_{2} \mathrm{O}^{25} .\end{array}\right.$ & $9.2-760$ & 0.000093 \\
\hline 5. $\left\{\begin{array}{l}\text { (A) } \mathrm{Mg}(\mathrm{OH})_{2} \rightleftarrows \mathrm{MrO}+\mathrm{H}_{2} \mathrm{O}^{25} \ldots \ldots \ldots \ldots \ldots \ldots \\
\text { (B) } \mathrm{Ba}(\mathrm{OH})_{2} \rightleftarrows \mathrm{BaO}+\mathrm{H}_{2} \mathrm{O}^{25} \ldots \ldots \ldots \ldots \ldots \ldots\end{array}\right.$ & $9.2-760$ & -0.000062 \\
\hline 6. $\left\{\begin{array}{l}\text { (A) } \mathrm{Fe}_{2}\left(\mathrm{SO}_{4}\right)_{3} \rightleftarrows \mathrm{Fe}_{2} \mathrm{O}_{3}+3 \mathrm{SO}_{3}\left[\mathrm{SO}_{2} \cdot \mathrm{O}_{2}\right]^{29} \ldots \ldots \ldots \ldots \\
\text { (B) } \mathrm{Al}_{2}\left(\mathrm{SO}_{4}\right)_{3} \rightleftarrows \mathrm{Al}_{2} \mathrm{O}_{3}+3 \mathrm{SO}_{3}\left[\mathrm{SO}_{2} \cdot \mathrm{O}_{2}\right]^{29} \ldots \ldots \ldots \ldots\end{array}\right.$ & $33-560$ & zero \\
\hline 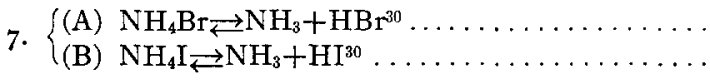 & $6-532$ & zero \\
\hline 8. $\left\{\begin{array}{l}\text { (A) } \mathrm{ZnSO}_{4} \rightleftarrows \mathrm{ZnO}+\mathrm{SO}_{3}\left[\mathrm{SO}_{2} \cdot \mathrm{O}_{2}\right]^{29} \ldots \ldots \ldots \ldots \ldots \ldots \\
\text { (B) } 2 \mathrm{AuCl} \rightleftarrows 2 \mathrm{Au}+\mathrm{Cl}_{2}{ }^{31} \ldots \ldots \ldots \ldots \ldots \ldots \ldots\end{array}\right.$ & $24-189$ & -0.00099 \\
\hline 9. $\left\{\begin{array}{l}\text { (A) } \mathrm{AgP}_{2} \rightleftarrows \mathrm{AgP}+\mathrm{P}^{32} \ldots \ldots \ldots \ldots \ldots \\
\text { (B) }{ }_{2} \mathrm{CuSO}_{4} \rightleftarrows 2 \mathrm{CuO}+2 \mathrm{SO}_{3}\left[\mathrm{SO}_{2} \cdot \mathrm{O}_{2}\right]^{29}\end{array}\right.$ & $59^{-2}$ I 4 & not constant \\
\hline
\end{tabular}

ably the surface tension of liquids. The agreement between the calculated and observed data presented in the preceding tables indicates that values obtained by this method represent a close approximation of the truth. The utility of the expression $R^{\prime}=R+c\left(T_{B}^{\prime}-T_{B}\right)$ is evident, for if values of one of the physical constants are known over a wide range of temperatures for one substance $(B)$, and if the value of the constant is determined at a few temperatures for a second substance $(A)$, then its value for the

${ }^{2 \pi}$ Tammann, G., “Krystallisieren und Schmelzen,” I903, p. 289.

${ }^{2 s}$ Jackson, C. G., J. Chem. Soc., 99, 1066 (I9II).

${ }^{20}$ Wöhler, L., W. Püddemann and P. Wöhler, Ber., 41, 703 (I908).

${ }^{30}$ Johnston, J., Z. physik. Chcm., 65, 38 (I909).

${ }^{31}$ Meyer, F., Compt. rend., 133, 817 (I901).

32 Granger, Ann. chim. phys., (7), 14, 5 (1901). 
latter can be calculated over a range corresponding to the range of the known values for the first substance $(B)$. To do this, the values of the ratio $T_{A}^{\prime} / T_{B}^{\prime}=R$ are plotted against the absolute temperatures $T_{E}^{\prime}$ and a straight line drawn through the points. By multiplying a particular temperature, $T_{B}^{\prime}$, by the corresponding temperature ratio (read off from the curve), the absolute temperature, $T_{A}^{\prime}$, is obtained at which the value of the physical constant of the substance $A$ is equal to that of the substance $B$ at the absolute temperature $T_{B}^{\prime}$. If the line does not run through the points (i.e., if $c$ is not constant), it is probable that the experimental data are not accurate, or that one of the substances behaves abnormally.

SWART H MORE, PA.,

March 16, I922.

The Atomic Process in Ferromagnetic Induction. SIR J. A. Ewing. (Proc. Royal Society, A 706.)-In 1890 the author brought to attention a model which embodied his conception of ferromagnetic irduction. In one plane it consisted of a group of similar, pivoted magnets. When no external magnetic force acts, these form configurations under the influence of their mutual attractions and repulsions, and when an external force is brought into action, as by the insertion of the group of magnets into a magnetizing coil, it is their mutual forces which must be overcome before the magnets can turn into the direction of the applied magnetizing force. Such a model simulated many of the phenomena manifested when a piece of iron is magnetized and, indeed, with striking completeness. Professor Ewing, however, finds that there is a great discrepancy between the magnetizing force really needed to make iron pass from the reversible to the irreversible stage and that which would be needed to accomplish the same change were the elementary magnets subject alone to their mutual attractions. He finds it necessary to place near each pivoted magnet two pairs of permanent magnets. Each pair has poles arranged thus, N S-S N and the axes of both magnets lie in the same line, but the directions of these lines are different for the two pairs. The pivoted magnet can turn within the magnets forming a pair without touching either. There is assumed to be a slight dissymmetry in the strength or in the position of the two magnets in the same line.

When it comes to seeking in the actual atom something akin to this highly artificial arrangement, it is suggested that a pair of electrons on opposite sides of the nucleus of the atom may correspond to the pivoted magnet, while groups of electrons farther away from the centre may play the rôle of the fixed magnets. The new type of model is far removed from the simplicity of its predecessors of 1890 , 